
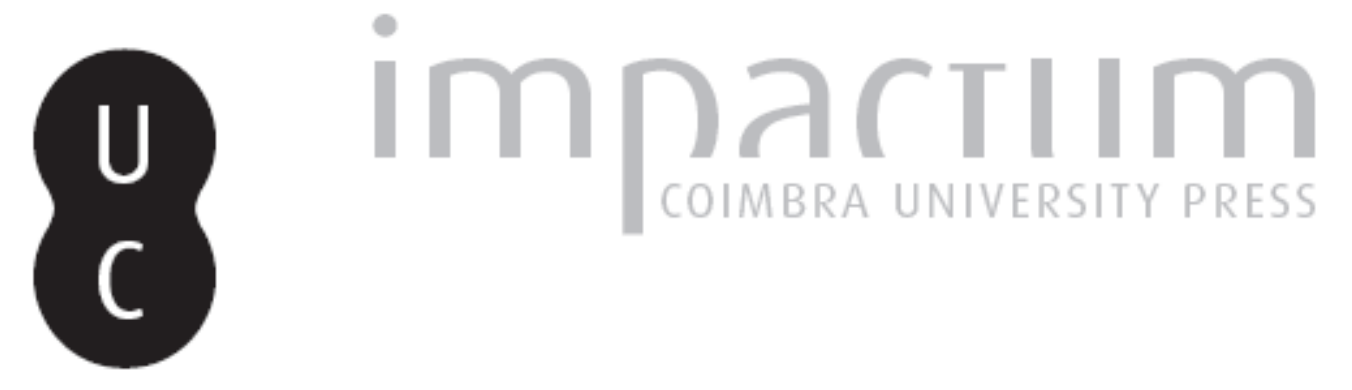

\title{
O tractatus de Wittgenstein na história da filosofia
}

Autor(es): $\quad$ Ribeiro, Henrique Jales

Publicado por: Imprensa da Universidade de Coimbra

URL persistente:

URI:http://hdl.handle.net/10316.2/42848

DOI:

DOI:http://dx.doi.org/10.14195/0872-0851_50_3

Accessed : $\quad$ 26-Apr-2023 15:42:41

A navegação consulta e descarregamento dos títulos inseridos nas Bibliotecas Digitais UC Digitalis, UC Pombalina e UC Impactum, pressupõem a aceitação plena e sem reservas dos Termos e Condições de Uso destas Bibliotecas Digitais, disponíveis em https://digitalis.uc.pt/pt-pt/termos.

Conforme exposto nos referidos Termos e Condições de Uso, o descarregamento de títulos de acesso restrito requer uma licença válida de autorização devendo o utilizador aceder ao(s) documento(s) a partir de um endereço de IP da instituição detentora da supramencionada licença.

Ao utilizador é apenas permitido o descarregamento para uso pessoal, pelo que o emprego do(s) título(s) descarregado(s) para outro fim, designadamente comercial, carece de autorização do respetivo autor ou editor da obra.

Na medida em que todas as obras da UC Digitalis se encontram protegidas pelo Código do Direito de Autor e Direitos Conexos e demais legislação aplicável, toda a cópia, parcial ou total, deste documento, nos casos em que é legalmente admitida, deverá conter ou fazer-se acompanhar por este aviso. 


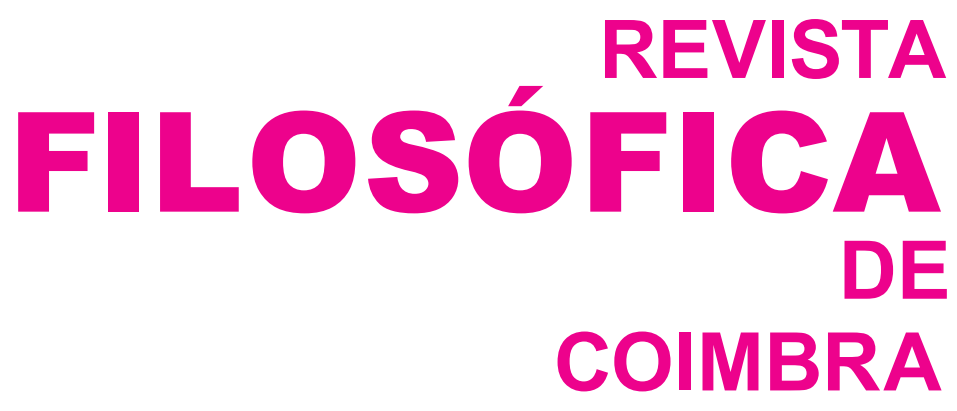

vol. 25 - número 50 - outubro 2016

vol. 25 - número 50 - outubro 2016

Fundação Eng. António de Almeida

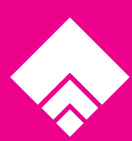




\title{
O TRACTATUS DE WITTGENSTEIN NA HISTÓRIA DA FILOSOFIA
}

\author{
WITTGENSTEIN'S TRACTATUS \\ IN THE HISTORY OF PHILOSOPHY
}

HENRIQUE JALES RIBEIRO*

\begin{abstract}
Ou o meu trabalho é uma obra da mais elevada categoria, ou não é uma obra da mais elevada categoria. No último (e muito mais provável) caso, eu próprio sou a favor de que não seja impresso. E, no primeiro caso, é indiferente que seja publicado vinte ou cem anos mais tarde ou mais cedo. No fim de contas, quem é que pergunta se a Crítica da razão pura, por exemplo, foi escrita no século $\mathrm{X}$ ou no século Y? Assim, realmente, também no primeiro caso o meu tratado não precisaria de ser impresso.

Ludwig Wittgenstein, Cartas a Russell, Keynes, e Moore ${ }^{1}$
\end{abstract}

Resumo: Neste artigo, o autor analisa o lugar do Tractatus Logico-Philosophicus na história da filosofia analítica e, mais geralmente, na história da filosofia ocidental. Uma vez questionados e revistos os pressupostos meta-históricos e metafilosóficos da primeira, a questão de saber qual é lugar dessa obra na segunda é ela mesma completamente reformulada. A teoria defendida, provocadoramente (em relação à historiografia conhecida), é que o problema central do Tractatus consiste nas funda-

* Professor no Departamento de Filosofia, Comunicação e Informação da Faculdade de Letras da Universidade de Coimbra. Contacto: jalesribeiro@gmail.com

1 "Either my piece is a work of the highest rank, or it is not a work of the highest rank. In the latter (and more probable) case I myself am in favor of its not being printed. And in the former case it's a matter of indifference whether it's printed twenty or a hundred years sooner or latter. After all, who asks whether the Critique of Pure Reason, for example, was written in the century X or Y? So really in the former case too my treatise wouldn't need to be printed." (Ludwig Wittgenstein, Letters to Russell, Keynes and Moore, ed. Georg H. von Wright (Oxford: Basil Blackwell, 1974), 88) 
ções últimas da filosofia através da lógica, e que este desiderato retoma em novos termos as conceções modernas, que vão de Descartes e Kant, a Frege e a Russell, sobre tais fundações.

Palavras-Chave: Descartes, fundações da filosofia, Kant, pós-modernidade, Russell, teoria da significação, Wittgenstein.

\begin{abstract}
In this article, the author analyses the place of the Tractatus Logico-Philosophicus in the history of analytic philosophy and, more generally, in the history of Western philosophy. After questioning and reviewing the metahistorical and metaphilosophical presuppositions of the former, the question of knowing what is the place of that work in the latter is itself reformulated. The theory defended, provocatively (in to regard to the known historiography), is that the central issue of the Tractatus are the final foundations of philosophy through logic, and that this desideratum resumes in new terms modern conceptions, from Descartes and Kant, to Frege and Russell, on such foundations.
\end{abstract}

Key-Words: Descartes, Kant, philosophical foundations, Russell, post-modernity, theory of meaning, Wittgenstein.
Résumé: Dans cet article, l'auteur examine la place du Tractatus Logico-Philosophicus dans l'histoire de la philosophie analytique et, plus généralement, dans l'histoite de la philosophie occidentale. Après avoir questionné et revu les presupposés métahistoriques et métaphilosophiques de la première, la question de savoir qu'elle est la place de cette oeuvre dans la séconde est complètement reformulée. La théorie proposée, de manière provocatrice (en ce qui concerne l'historiographie connue), c'est que le problème central du Tractatus ce sont les fondations ultimes de la philosophie à travers la logique, et que cet objectif reprend en des termes renouvelés les conceptions modernes, de Descartes et Kant, à Frege et Russell, sur cettes fondations.

Mot-clés: Descartes, fondations philosophiques, Kant, postmodernité, Russell, théorie de la signification, Wittgenstein.

\section{Introdução}

Neste artigo, na sequência de investigações feitas ao longo dos anos com vários pretextos e às quais se aludirá, procura-se elucidar a questão de saber qual é o lugar do Tractatus Logico-Philosophicus, de Ludwig Wittgenstein, na história da filosofia ocidental, em particular, qual é o enquadramento histórico-filosófico dessa obra no contexto em que foi produzida e publicada e a forma como esse enquadramento pode ser interpretado e projetado na história referida. A questão está longe de ser inofensiva e pacífica, como se 
verá. Desde a sua elaboração, ainda antes da publicação e a começar pela "Introdução" de Russell, o Tractatus foi sempre matéria de leituras e comentários discutíveis e controversos, que têm fundamentalmente a ver, não tanto com a obra em si mesma mas, se é possível divorciar as duas coisas, com os respetivos contextos de interpretação. Para dar dois exemplos, que analisaremos posteriormente em detalhe: numa primeira fase, que vai até ao final dos anos setenta do século passado, foi lido como se se enquadrasse no contexto da filosofia do atomismo lógico de Russell, que continuaria e desenvolveria em novos termos; ${ }^{2}$ numa segunda, a partir dessa altura, foi interpretado em clara rutura com essa filosofia, e, no âmbito daquilo a que Rorty e outros virão a chamar "viragem linguística", ${ }^{3}$ como inaugurando as investigações contemporâneas em matéria de filosofia da linguagem e da teoria analítica da significação muito em especial. ${ }^{4}$ Surpreendentemente, houve reputados comentadores, como é o caso de D. Pears, que, dada a sua grande longevidade filosófica, parecem ter subscrito sucessivamente as duas interpretações, como se não existisse qualquer conflito entre elas. ${ }^{5} \mathrm{Na}$ perspetiva da primei$\mathrm{ra}$, e como atesta de resto a historiografia filosófica da época, Wittgenstein seria uma figura menor ou secundária, sem grande relevo; ${ }^{6}$ na da segunda, estaria diretamente na origem de toda uma tradição filosófica inteiramente nova (a tradição analítica em filosofia). ${ }^{7}$ É claro, para nós hoje em dia, que uma coisa é confinar a importância do Tractatus ao programa (ou programas) de investigação de Russell, outra, bem diferente, é vê-lo como encabeçando uma tal tradição, como é o caso da da filosofia analítica; não porque as duas coisas se excluiriam reciprocamente e não haveria sombra de compromisso entre elas (o que, como se mostrará neste trabalho, está longe de ter aconte-

2 Ver David Pears, "Logical Atomism: Russell and Wittgenstein", in: The Revolution in Philosophy, ed. Alfred J. Ayer et al. (London: MacMillan, 1956), 41-55. Sobre o assunto, cf. Eli Friedlander, Signs of Sense: Reading Wittgenstein's 'Tractatus' (Cambridge-Massachusetts/London: Harvard University Press, 2001), 168-170.

3 Richard Rorty (ed.), The Linguistic Turn: Recent Essays in Philosophical Method (Chicago: The University of Chicago Press, 1975).

4 Peter Hacker, Wittgenstein's Place in Twentieth-Century Analytic Philosophy. (Oxford: Blackwell, 1996).

5 Veja-se o último livro desse autor sobre Wittgenstein: David Pears, The False Prison. A Study of the Development of Wittgenstein's Philosophy (Oxford: Oxford University Press, 1987).

6 Veja-se James O. Urmson, "Histoire de l'analyse", in: La philosophie analytique, org. Jean Whal et al. (Paris: Les Éditions de Minuit, 1962), 11-22. Cf. idem, Philosophical Analysis: Its Development Between the Two World Wars (Oxford: Clarendon Press, 1956).

7 Veja-se Hans-Johann Glock, What is Analytic Philosophy? (Cambridge: Cambridge University Press, 2008), 34-37; idem (ed.), The Rise of Analytic Philosophy. (Oxford: Blackwell Publishers Inc., 1997). 
cido), mas porque, dessa forma, não chegaríamos verdadeiramente a compreender a originalidade da obra. Em todo o caso, a segunda interpretação, que é, sem dúvida a mais atual e corrente, levanta problemas tremendos do ponto de vista daquilo a que podemos chamar uma "história da história da filosofia", entre os quais o de saber como é que a tradição a que aludimos se inserirá ela mesma no contexto mais amplo da história da filosofia ocidental. O ponto essencial, que cumpre salientar, parece ser o de que as leituras filosóficas, quaisquer que elas sejam, são sempre feitas em contexto, resultando de projeções nas obras dos autores em estudo de premissas que em parte têm a ver, não com essas obras em si mesmas, mas, como se disse, precisamente com esses contextos de interpretação. ${ }^{8}$ (Para além da filosofia analítica propriamente dita, um outro exemplo desse tipo de contextos, que interessa particularmente para o estudo de Russell, é o da "tradição do empirismo britânico em filosofia", que foi proposto por Ayer nos anos trinta, e analisei atentamente em vários trabalhos. $)^{9}$ Ter a consciência hermenêutica adequada das projeções em causa é absolutamente essencial para o historiador da filosofia, por forma a, tanto quanto possível e se tal é viável, saber distinguir o que pertence ao autor ou filósofo, e à época respetiva, do que pertence à própria época ou contexto de interpretação do comentador. Mas mais geralmente: essa consciência permite-lhe pôr em conflito, dialeticamente falando (quer dizer, comparando-as ou confrontando-as), as interpretações filosóficas envolvidas, inferindo daí o que é possível inferir para a compreensão da obra ela mesma do filósofo em estudo. A historiografia filosófica, como já foi defendido por alguns reputados comentadores e historiadores, pode ser sistemática, deste último ponto de vista, e ter a maior pertinência e alcance filosóficos. ${ }^{10}$ É a partir dele que as interpretações do Tractatus serão analisadas no presente trabalho.

8 Ver Henrique Jales Ribeiro, "Towards a Reformulation of the Analytic Concept of the History of Philosophy", in Proceedings of the International Congress 'Analytic Philosophy at the Turn of the Millenium" (Santiago de Compostela: Universidad de Santiago de Compostela, 1999), 493-501.

9 Alfred J. Ayer, "The Analytic Movement in Contemporary British Philosophy", in: Actes du Congrès International de Philosophie Scientifique (Sorbonne) (Paris: Hermann, 1935). Veja-se igualmente idem, The Foundations of Empirical Knowledge (London: MacMillan, 1940); idem (ed.), The Revolution in Philosophy (London: MacMillan, 1956); e idem, Russell and Moore: The Analytic Heritage (London: MacMillan, 1971). Para uma interpretação global do assunto, veja-se Henrique Jales Ribeiro, "Locke, a tradição do empirismo britânico e a filosofia analítica", in: Actas do Colóquio Internacional 'A Herança de Locke' (Proceedings of the International Colloquium 'Locke's Legacy') (Lisboa: Faculdade de Letras da Universidade de Lisboa, 2005), 39-60.

10 Veja-se Martial Gueroult, Dianoématique (Livre II: Philosophie de l'histoire de la philosophie (Paris: Aubier, 1979). 


\section{O preconceito analítico na historiografia filosófica}

Voltando a Rorty e à sua introdução a $A$ viragem linguística-livro publicado em 1967. Significativamente, depois do que foi dito, a filosofia de Wittgenstein, no Tractatus em particular mas também nas Investigações filosóficas, não tem nesse livro qualquer importância ou relevo, em comparação com a de outros autros autores, menores, que não ficaram para a história da filosofia (a chamada "história monumental") e são hoje em dia praticamente desconhecidos. Wittgenstein só entrará em cena cerca de uma década mais tarde. (O mesmo tipo de observação, quanto esse grande filósofo, poderia ser feito tendo como pretexto outras reputadas historiografias filosóficas da época. ${ }^{11}$ Porque razões? Basicamente porque o contexto, ao tempo, não era favorável ou propício a que tal acontecesse, quer dizer, não havia uma grelha de leitura que pudesse destacar a importância e originalidade de Wittgenstein. Vai ser necessário esperar que a problemática da teoria da significação, e a do holismo em particular, proveniente das mais diversas fontes, mas da filosofia de Quine em particular, entre ela mesma em cena na história da filosofia. Vai ser necessário esperar por aquilo a que nos habituámos a chamar nas últimas décadas "pós-modernidade em filosofia" (que é um fenómeno cultural e interdisciplinar complexo, e tem outras vertentes, para além da filosófica). Alguns trabalhos de Quine nos anos cinquenta, como "Dois dogmas do empirismo" e, sobretudo, o livro Relatividade ontológica e outros ensaios nos final dos anos sessenta, desempenharam, nesta matéria, um papel absolutamente crucial, mostrando claramente que é essa problemática que está no cerne da filosofia da linguagem e das fundações da filosofia de maneira geral. ${ }^{12}$ (Sem surpresa, Quine, que, em contraste com Wittgenstein, sempre teve relações de estreita colaboração com o que Dummett apelidou a dada altura a "filosofia inglesa da linguagem corrente" [Austin, Ryle, e outros $],{ }^{13}$ tem um lugar de relevo em $A$ viragem linguística, bem como noutras coletâneas da mesma época. ${ }^{14}$ Era possível reler, a esta luz, as obras de Wittgenstein, aí incluindo o Tractatus, de uma perspetiva completamente

11 Veja-se Anthony Flew (ed.), Logic and Language (Oxford: Basil Blackwell, 1953).

12 Veja-se Willard van O. Quine, "Two dogmas of Empiricism", in: From a Logical Point of View (Cambridge-Massachusetts: Harvard University Press), 1-19; idem, "Le mythe de la signification", in: La philosophie analytique, org. Jean Wahl et al. (Paris: Les Éditions de Minuit, 1962), 138-169; e idem, Ontological Relativity and Other Essays (New York: Columbia University Press, 1969). Para um paralelo entre as conceções de Quine e as de Wittgenstein em matéria de holismo, veja-se Robert L. Arrington and HansJohann Glock (eds.), Wittgenstein and Quine (London and New York: Routledge, 1996).

13 Michael Dummett, Truth and Other Enigmas (London: Duckworth, 1978), 432-433.

14 Veja-se Rorty, The Linguistic Turn, 168-172. E H. D. Lewis (ed.), Clarity is not Enough: Essays in Criticism of Linguistic Philosophy (London: George Allen \& Unwin Ltd., 1963), 100-131. 
diferente da tradicional, isto é, da filosofia do atomismo lógico de Russell, como tinha feito Pears nos seus primeiros trabalhos. Importa assinalar desde já, como veremos melhor de seguida, que essa filosofia, que não deixa de ter um impacto significativo no Tractatus (como mostram logo as suas três primeiras secções sobre a teoria da proposição), estava longe de poder identificar-se quer com os problemas desta obra de maneira geral (o estatuto metafilosófico da lógica, as questões relacionadas com a ética, etc.), quer, principalmente, com aqueles que estão na origem e desenvolvimento da filosofia de Russell ela mesma a partir de 1900, de Os princípios da matemática (1903) a $O$ nosso conhecimento do mundo externo (1914). Os problemas de Russell, desde essa época, têm a ver eles próprios, em parte pelo menos, com questões como as de Wittgenstein, no Tractatus e nas Investigações filosóficas, sobre a teoria da significação e as fundações da filosofia.

O Tractatus, em princípio, entrou para a história da filosofia ocidental através do que se passou a chamar a partir dos anos setenta do século passado a "história da filosofia analítica"; contudo, como alegarei mais à frente, considerando que os historiadores desta última filosofia a dissociam claramente da primeira, a pretexto do conhecido divórcio entre "filosofia analítica", por um lado, e "filosofia continental", por outro, sempre ficou em aberto, de certo modo, a questão de saber qual será o verdadeiro lugar dessa obra no mais amplo contexto do pensamento ocidental de Platão e Aristóteles, a Frege e a Russell, passando por Descartes, Kant, Hegel. (Esta é uma consequência paradoxal da historiografia analítica nas últimas décadas e da constituição da "tradição analítica em filosofia" como uma tradição completamente separada e distinta da da "tradição continental".) E, de facto, só excecional e episodicamente aqueles que se reclamam expressamente da filosofia analítica procuram enquadrar o Tractatus nesse contexto (não é o caso de Pears, como mostra o seu último magnífico trabalho sobre Wittgenstein: A falsa prisão). A conceção oficial é que ele constituirá de algum modo a proto-história da filosofia analítica contemporânea de modo geral, quer dizer, configurará um período fundador e normativo que conterá em germe, mais ou menos potencialmente, o campo de problemas que está subjacente ao desenvolvimento da mesma. (É assim que P. Hacker, talvez o mais prestigiado comentador de Wittgenstein atualmente, a vê.) E aí, como já sugeri, a teoria da significação no Tractatus desempenhará um papel absolutamente fundamental; porque é precisamente dessa teoria que, desta ou daquela maneira, se tratará ao longo do referido desenvolvimento, da filosofia inglesa da linguagem corrente (nos anos 50), a Quine, Putnam e outros. Agora, que o conceito de história da filosofia analítica, tal como o podemos apreender ainda hoje em dia, é uma construção histórico-filosófica que foi progressivamente elaborada, que ele, pois, é um constructo e não uma entidade ou realidade qualquer historicamente subsistente por si mesma e virgem ou imune em relação às nossas interpretações (como, ingénua e desprevenidamente, somos levados a a pensar 
à primeira vista), é algo que mostra o seu nascimento e evolução dos finais dos anos sessenta aos nossos dias, isto é, ao longo dos últimos cinquenta anos. ${ }^{15}$ Como se disse, antes desta época, onde se inclui significativamente toda a filosofia de Wittgenstein (que era um autor austríaco e, portanto, geograficamente "continental") do Tractatus às Investigações, não há "história da filosofia analítica" nem, de resto e em rigor, haverá "filosofia analítica"-o que alguma historiografia analítica (como é o caso da de Hacker) admite e reconhece de bom grado, se bem que não retire daí todas as consequências que importa retirar. ${ }^{16}$ Uma delas, talvez a mais importante, é a função ideológico-institucional, caracteristicamente manipuladora, que o conceito de "filosofia analítica" passa a assumir: passam a existir modelos e critérios para avaliar a produção filosófica, designadamente aquela que não se conforma com a proto-história a que aludimos acima, e seus desenvolvimentos, como é o caso, desde logo, da de Bertrand Russell. (Entre os modelos e critérios a que me refiro consta o da historiografia de $\mathrm{M}$. Dummett, já aqui mencionada, nos anos setenta e oitenta.) ${ }^{17}$ Outra, é que a tradição analítica em filosofia passa a ter uma identidade social, cultural e política, claramente distinta, mais uma vez, da chamada "tradição continental" (um assunto, que abordei noutros lados, e que não estará em questão neste trabalho). ${ }^{18} \mathrm{Um}$ ponto essencial que diz respeito à primeira é que a historiografia filosófica aparece-nos como um instrumento de legitimação da própria filosofia analítica e da leitura que é possível fazer do Tractatus ao abrigo da mesma: inserir essa obra no contexto mais amplo da história da filosofia ocidental, portanto, mostrar as suas conexões e compromissos mais ou menos estreitos com a filosofia continental, está fora de questão, à partida, para essa historiografia. Segundo esta conceção, a filosofia, ou a filosofia que vale a pena fazer na época contemporânea, começa, de facto, com Wittgenstein e seus diretos antecessores (não propriamente Russell mas, sobretudo, Frege). ${ }^{19}$

15 Veja-se, deste ponto de vista, uma breve história do conceito de filosofia analítica (“Analytic Philosophy: A Historico-Critical Survey") em Georg H. von Wright, The Tree of Knowledge and Other Essays (Leiden/New York/Köln: E. J. Brill, 1993), 41 e ss.

16 Veja-se Hacker, Wittgenstein's Place, nota 2.

17 Vejam-se os trabalhos coligidos em Dummett, Truth; idem, Frege: Philosophy of Language (London: Duckworth, 1981); e idem, Les origines de la philosophie analytique, trad. M.-A. Lescourret (Paris: Gallimard, 1991).

18 Veja-se David Follesdal, "Analytic Philosophy: What is and Why Should One Engage on It?", in: The Rise of Analytic Philosophy, ed. Hans-Johann Glock (Oxford: Blackwell Publishers Inc., 1997), 193-208; e Henrique Jales Ribeiro, Para compreender a história da filosofia analítica (Coimbra: MinervaCoimbra, 2001).

19 Para uma crítica desta conceção, veja-se idem, "Não há método nem métodos da filosofia analítica: Não há filosofia analítica", in: Actas do Colóquio 'Método e Métodos do Pensamento Filosófico' (Faculdade de Letras da Universidade de Coimbra, 26-27 de abril de 2006), org. Diogo Ferrer (Coimbra: Imprensa da Universidade de Coimbra, 2007), 119-135. 


\subsection{O Tractatus revisitado: Russell vs. Wittgenstein}

Para a historiografia analítica a partir dos anos setenta do século passado, dada a eleição da proto-história a que me referi anteriormente, a tarefa, desde logo, consistia em destacar a originalidade da filosofia do Tractatus em contraste com a filosofia de Russell, como, de novo, se não existissem compromissos mais ou menos fundamentais entre ambas, que têm a ver não só com a época e respetivo contexto mas também, e principalmente, com a própria história da filosofia ocidental no seu conjunto. Anedoticamente: o Tractatus terá provocado a "bancarrota" ou o "colapso" da filosofia de Russell, ao tempo: e, na mesma perspetiva e por outro lado, tudo o que seria de origem russelliana nessa obra deveria ser expurgado, porque inapropriado, ou completamente reinterpretado. ${ }^{20} \mathrm{Em}$ vários trabalhos defendi, quanto à primeira alegação, o seu carácter completamente disparatado: a filosofia de Russell, depois da receção do manuscrito do Tractatus e da "Introdução" ao mesmo, estava mais viva do que nunca, como prova a elaboração do livro $A$ análise da mente (1920-1921), onde, de resto, o autor antecipa, do seu próprio ponto de vista, algumas teses que só virão a ser desenvolvidas por Wittgenstein décadas mais tarde, como é o caso da que a significação resulta fundamentalmente do uso da própria linguagem. ${ }^{21}$ (E Russell, como se sabe, só viria a abandonar a filosofia cerca de quarenta anos depois da sua "Introdução" ao Tractatus, por altura da publicação de $O$ meu desenvolvimento filosófico. $)^{22}$ Esta leitura, em contraste com as historiografias conhecidas, põe o filósofo inglês merecidamente em vivo diálogo com a filosofia do seu tempo, pelo menos, durante toda a primeira metade do século XX. A segunda alegação, contra leituras correntes dos anos trinta em diante no âmbito anglo-saxónico (Urmson, nos anos sessenta, falará de uma "escola de Cambridge", que teria supostamente o patrocínio filosófico de Russell), ${ }^{23}$ como é o caso da de Pears, a que já aludi, passa por atribuir ao Tractatus, por antecipação, a tese fundamental das Investigações filosóficas: a de que o tema fundamental e decisivo da filosofia é a linguagem e a teoria da significação em particular. (Não se rejeitam as grandes diferenças entre as duas obras, que pressupõem, com a segunda, o aparecimento de uma perspetiva naturalista e behavio-

20 Veja-se Peter Hylton, "Logic in Russell's Logicism”, in: The Analytic Tradition: Meaning, Thought, and Knowledge, eds. David Bell and Neil Coopper (Cambridge-Massachusetts, 1990), 137-192.

21 Henrique Jales Ribeiro, "Russell, o Tractatus de Wittgenstein e o problema do holismo em filosofia", Revista Portuguesa de Filosofia 58 (2002), 465-495.

22 Veja-se Russell, Bertrand, My Philosophical Development (London: Routledge, 1959).

23 Veja-se Urmson, "Histoire", 18. 
rista em matéria de significação, mas elege-se a teoria sobre esta como o enquadramento comum das mesmas. ${ }^{24}$ Deste ponto de vista se entenderão a ontologia, a metafísica e a epistemologia do primeiro trabalho, que são claramente postas em questão pelo segundo: não se tratará, como na leitura russelliana da filosofia do atomismo lógico, que em parte Pears tinha começado por subscrever, de continuar ou desenvolver conceções como as de $O$ nosso conhecimento do mundo externo (1914) ou "A filosofia do atomismo lógico" (1918), ${ }^{25}$ mas, em rutura completa com as mesmas, de destacar precisamente a importância fundamental da referida teoria para uma visão inteiramente nova e revolucionária da filosofia. Russell não estaria interessado numa filosofia da linguagem nem numa teoria da significação por si mesmas, fazendo delas o tema central da investigação filosófica, uma vez que as duas serão postas ao serviço, por ele, dos mesmos desideratos da filosofia tradicional, em especial o cartesiano e kantiano do nosso "conhecimento do mundo externo". Não podendo recusar, em qualquer caso, que se trata, de facto, de matérias desse tipo no Tractatus (como é possível constatar logo nas duas primeiras secções), os comentadores que defendem a última alegação, a que aludimos, sugerem que, em contraste com o que se passará com o filósofo inglês, as mesmas estarão isentas das "inconsistências" e "contradições" que atravessam os textos que mencionámos por último. (Tratar-se-á, se o conceito faz algum sentido, de ontologia, metafísica e epistemologia "puras", que passam pela eliminação do que, numa filosofia como a do atomismo lógico, é o papel da ideia de sujeito de conhecimento.) A "Introdução" de Russell ao Tractatus aparece, neste contexto, como um texto chave para os críticos wittgensteinianos desse filósofo ao longo dos últimos quarenta anos: porque ele, alegadamente, não terá compreendido a perspetiva fundamental de Wititgenstein nesse livro, segundo a qual a linguagem corrente estará "em ordem, tal como está", e não carece de qualquer correção ou reformulação, como aquelas que uma "linguagem logicamente perfeita", como é suposto serem a de os Principia Mathematica e a que o positivismo lógico vienenese na sequência desse livro subscreverá, proporcionaria. ${ }^{26}$ (Noutros trabalhos já

24 Para além de Hacker, Wittgenstein's Place, veja-se um desenvolvimento da mesma ideia por parte desse autor em Peter Hacker, Wittgenstein: Connections and Controversies (Oxford: Clarendon Press, 2001), 1-33.

25 Bertrand Russell, Our Knowledge of the External World as a Field for Scientific Method in Philosophy (Chicago and London: The Open Court Publishing Co., 1914); idem, "The Philosophy of Logical Atomism", in: Bertrand Russell: The Philosophy of Logical Atomism and Other Essays (1914-1919), The Collected Papers of Bertrand Russell, vol. 8, ed. John Slater (London: George Allen and Unwin, 1986), 160-244.

26 Veja-se Teresa Iglesias, "Russell's Introduction to Wittgenstein's Tractatus", Russell: The Journal of the Bertrand Russell's Archives 25-28 (1977), 21-38; idem, "Russell and Wittgenstein: Two Views of Ordinary Language", Philosophical Studies XVIII 
mostrei que esta imputação não tem fundamentação filosófica e é completamente inapropriada, porque também para Russell, por volta de 1918-1920, a linguagem está "em ordem, tal como está". ${ }^{27}$ Mas, para os seguidores de Wittgenstein, a tese em questão deve ser considerada na perspetiva da teoria da significação nas Investigações: em contraste com Russell e o positivismo, já no Tractatus se despede a lógica como instrumento de investigação da linguagem corrente e se antecipa uma tal teoria como o tema central da investigação filosófica. $)^{28}$ A consequência de tudo isto, como já referi, é: "bancarrota" da filosofia de Russell com a publicação do Tractatus; exclusão de Russell do desenvolvimento mais geral das ideias filosóficas durante todo o século XX. Mas o que é que existirá de "russelliano" nessa obra, no sentido sistemático do conceito de filosofia, que é aquele que de facto importa? O que é que haverá de comum, com ela, entre o "programa" de Russell, que o filósofo consubstancia, em $O$ nosso conhecimento do mundo externo, na famosa expressão de que "a lógica é a essência da filosofia" e, por outro lado, o "programa" de Wittgenstein, apesar de todas as conhecidas divergências entre ambos? Tendo retirado ao estudo do contexto histórico-filosófico onde se insere o Tractatus, e sem o qual este não pode ser compreendido, um interesse filosófico verdadeiramente positivo, eliminado virtualmente todos os compromissos e cumplicidades de Wittgenstein com o mesmo, que outras conexões, com o passado da história da filosofia ocidental, particularmente

(1981), 148-163; Hacker, Wittgenstein's Place, cap. 3, 39-66; Henrique Jales Ribeiro, "A New Reading of Russell's 'Introduction' to Wittgenstein's Tractatus", in: Time and History: Papers of the 28th International Wittgenstein Symposium, eds. Friedrich Stadler and Michael Stöltzner (Kirchberg am Wechsel: Austrian Ludwig Wittgenstein Society, 2005), 256-257; idem, Bertrand Russell e a filosofia analitica no século XX (Coimbra: Pé de Página Editores, Lda., 2007); idem, "Russell vs. Wittgenstein: In Defense of Russell (A Reply to Some Old Thesis of Peter Hacker's Interpretation of Wittgenstein's Tractatus)", in: Image and Imaging in Philosophy, Science, and the Arts: Papers of the 33rd International Wittgenstein Symposium, eds. Elisabeth Nemeth, Richard Heinrich and Wolfram Pichler (Kirchberg am Wechsel: Austrian Ludwig Wittgenstein Society, 2010), 268-270.

27 Veja-se idem, "Da 'imagem oficial' de Russell à reabilitação da sua filosofia: 'O vago' como caso em estudo", in: Da natureza ao sagrado (Homenagem a Francisco Vieira Jordão) (Porto: Fundação Eng. António de Almeida, 1999), 199-257; e idem, "Russell, Wittgenstein e a ideia de uma 'linguagem logicamente perfeita'", Revista Filosófica de Coimbra 27 (2005), 81-130.

28 Contudo, numa significativa passagem das Investigations, Wittgenstein atribui a si próprio, no Tractatus, justamente uma perspetiva contrária a esta: "It is interesting to compare the multiplicity of the tools in language and of the way they are used, the multiplicity of kinds of word and sentence, with what logicians have said about the structure of language. (Including the author of the Tractatus Logico-Philosophicus.)" (Ludwig Wittgenstein, Philosophical Investigations, ed. G.E.M. Anscombe and R. Rhees, transl. G.E.M. Anscombe (Oxford: Blackwell, 1953), 128, § 23) 
com a época moderna, de Descartes a Kant e a Hegel, isto é, com a filosofia propriamente "continental", terá o trabalho de Wittgenstein? A historiografia analítica, fazendo do mesmo o ponto de partida da tradição analítica em filosofia, não dá, porque não está interessada à luz das razões que já apresentei anteriormente, qualquer resposta a estas questões.

\subsection{A função ideológica da historiografia filosófica sobre o Tractatus}

Um ponto essencial do que disse até aqui, e que importa esclarecer antes de prosseguir, é a função ideológica, institucionalmente legitimadora, da historiografia sobre o Tractatus feita ao abrigo do paradigma analítico em filosofia. A ideia central, que explanei em vários trabalhos, é que essa historiografia desempenha um papel claramente institucional no quadro universitário anglo-saxónico na defesa e legitimação da própria tradição analítica em filosofia. (É esse o papel do Tractatus como proto-história desta tradição.) Gellner, nos anos cinquenta do século passado, começou por chamar a atenção, numa perspetiva sociológica, para o assunto, que foi retomado por vários autores nas últimas décadas. ${ }^{29}$ Uma tal função, nas universidades anglo-saxónicas que corporizam a referida tradição, passa por manter e desenvolver a mesma, eventualmente excluindo aquelas leituras e interpretações que não se conformam com ela; que não são "analíticas" no sentido concetual rigoroso do conceito. ${ }^{30}$ (A exclusão de Russell do movimento analítico, por parte dos próprios filósofos analíticos de maneira geral, insere-se neste contexto.) Já a "tradição do empirismo britânico", de Ayer, a que aludi mais acima, parecia desempenhar precisamente um tal papel, aparecendo como o enquadramento legitimador do verdadeiro lugar de Locke, Berkeley e Hume na história da filosofia. (A historiografia que não se subordinava a tal paradigma poderia ser menosprezada e, potencialmente pelo menos, excluída.) Para um filósofo "continental", na aceção analítica do termo, o que estamos a dizer é surpreendente à primeira vista, porque as conceções institucionais da filosofia (o modo como a filosofia é concebida e praticada nas instituições em que é ensinada) não serão, em princípio, elas mesmas filosoficamente relevantes. ( $\mathrm{O}$ assunto só episódica e excecionalmente é referido pela historiografia dita continental, como é o caso da de K. Mulligan, o que

29 Ernest Gellner, Words and Things. A Critical Account of Linguistic Philosophy, and a Study in Ideology, with and Introduction by Bertrand Russell (Bungay-Suffolk (UK): Victor Gollancz, 1959).

30 Veja-se a este respeito Jonathan Rée, "La philosophie anglaise des années cinquante", in: Philosophie analytique et histoire de la philosophie, ed. Jean-Michel Vienne (Paris: Vrin, 1997), 17-59. 
mostra bem que os filósofos continentais, de maneira geral, não the atribuem grande interesse filosófico. $)^{31}$ Disse, "em princípio", porque a historiografia filosófica continental de maneira geral tem, no fundo, a mesma função legitimadora, que passa normalmente despercebida, considerando que tem como objeto o amplo contexto da história da filosofia ocidental, e não esta ou aquela tradição em especial. ( $\mathrm{Na}$ sociologia de Kuhn, de um ponto de vista muito similar ao meu, mostra-se a conexão essencial entre a ciência, como produção teórica revolucionária, e as suas interpretações institucionalmente legitimadoras, no quadro do que esse autor chama a "ciência normal". ${ }^{32} \mathrm{O}$ que estou a defender é que o mesmo tipo de categorias pode e deve ser aplicado à filosofia, conduzindo, em parte pelo menos, às mesmas consequências que Kuhn retira.) Na verdade, o que acontece é que a historiografia filosófica, analítica ou continental, não deve ser encarada como uma coisa à parte e estranha à própria produção filosófica; quer dizer, como o simples papel e dever do comentador em contraste com os do filósofo propriamente dito. (É por aqui que passa a conhecida controvérsia entre os dois campos, nos anos sessenta e setenta sobretudo, segundo a qual a filosofia no continente seria essencialmente história da filosofia, e a analítica, por outro lado, ignoraria a história, senão mesmo seria anistórica, porque seria criativa e original. ${ }^{33}$ Essa controvérsia, hoje em dia, não faz qualquer sentido, como mostra a ampla produção historiográfica analítica, para além da continental, sobre a própria história da filosofia analítica.) Legitima historicamente estes últimos no plano institucional e, designadamente, universitário, aparecendo como o "verdadeiro texto", a "verdadeira narrativa", aquela que importa desocultar e trazer originalmente à luz.

\section{As leituras do Tractatus na pós-modernidade}

Significativamente (do ponto de vista em que aqui me coloco e que comecei por apresentar na introdução a este trabalho) as grandes alterações das grelhas de leitura, de maneira geral, do Tractatus, e da analítica em particular, foram feitas à margem da própria tradição analítica, senão mesmo foram feitas contra esta; de facto, foram apresentadas com pressupostos

31 Veja-se Kevin Mulligan, "Sur l'histoire de l'approche analytique de l'histoire de la philosophie (de Bolzano et Brentano à Bennett et Barnes", in: ibidem, 61-84; idem, "Introduction: On the History of Continental Philosophy", Topoi 2 (2009), 115-120.

32 Thomas Kuhn, The Structure of Scientific Revolutions (Chicago: Chicago University Press, 1962); idem, A tensão essencial, trad. R. de Pacheco (Lisboa: Edições 70, 1989).

33 Veja-se alguns dos textos e das discussões em Jean Wahl et al. (org.), La philosophie analytique (Paris: Les Éditions de Minuit, 1962). 
meta-históricos e metafilosóficos inteiramente diferentes dos dessa tradição, e independentemente de qualquer leitura, comentário e interpretação dessa obra. Refiro-me à historiografia, aparecida nos anos setenta do século passado, que procurou integrar o movimento analítico ele mesmo no seu conjunto e desde as suas (supostas) fundações, com Frege e com Russell, no âmbito mais geral da história da filosofia ocidental, e de que o exemplo mais notável é o livro de Rorty A filosofia e o espelho da natureza-o mesmo autor que introduziu no final dos anos sessenta o conceito proto-histórico de "viragem linguística", a que já aludi por várias vezes. ${ }^{34} \mathrm{O}$ mérito de Rorty, no seu segundo livro, passa, desde logo, por enquadrar historicamente a filosofia analítica ou a sua "tradição" nesse âmbito ou contexto partilhado pela "filosofia continental", mostrando que só de forma acessória ou secundária ("retórica", se se preferir) se pode falar das mesmas como constituindo entidades autónomas e divorciadas dessa "filosofia". ${ }^{35}$ No livro referido, a "história da filosofia analítica", que não se pode reduzir aos autores e temas editados e abordados dez anos antes em $A$ viragem linguística, passa, com ele, a fazer parte, por direito próprio, da "história da filosofia ocidental"; na verdade, aparece aí significativamente como o capítulo derradeiro ou final da mesma, para todos os efeitos, aquele que, de acordo com a interpretação desse autor, marca o fim da própria filosofia ocidental, de Platão e Aristóteles aos nossos dias, entendida como investigação sistemática. (Tudo isto não quer dizer, muito pelo contrário, que as teorias de Rorty tivessem sido aceites pelos filósofos analíticos de maneira geral. As conceções destes mantiveram-se fiéis às ideias que analisei na secção 2 deste artigo, como mostra alguma historiografia analítica recente, e a de Glock em particular.) $)^{36}$ Os pressupostos histórico-filosóficos fundamentais, nos nossos dias, da filosofia analítica e da continental serão essencialmente os mesmos: a modernidade cartesiana e kantiana, e a ideia de que a filosofia pode fundar os restantes saberes (como na famosa "árvore" de Descartes, em os Princípios da filosofia, se defende) $)^{37}$ e, por esta via, o conhecimento do mundo e a ação humana no seu conjunto, através de um quadro neutral de investigação, qualquer que ele seja (porque, na verdade, esse quadro foi diversamente concebido desde os séculos

34 Richard Rorty Philosophy and the Mirror of Nature (Princeton (NJ): Princeton University Press, 1979).

35 Rorty, Philosophy, cap. VI, 257 e ss.

36 Glock, What is?, 3-20. Cf. A. P. Martinich, "Introduction", in: A Companion to Analytic Philosophy, ed. A.P. Martinich and David Sosa (Oxford: Blackwell Publishers, 2001), 1-5.

37 René Descartes, The Philosophical Writings of Descartes, vol. I, transl. J. Cottingham, R. Stoothoff, and D. Murdoch (Cambridge: Cambridge University Press, 1985), 177 e ss. 
XVII-XVIII à época contemporânea, embora tenha tido, desde o início, uma moldura basicamente kantiana, que é a da "lógica transcendental" da Crítica da razão pura),${ }^{38}$ mas aí incluindo a lógica matemática de Frege e de Russell e, por extensão e compreensão, a própria "lógica filosófica" do Tractatus. São esses os pressupostos e, em especial, é essa a conceção fundacional e sistemática da filosofia (o que significa ou implica que a filosofia analítica, ou a respetiva tradição, sempre tiveram o "inimigo" [i.é, Descartes, Kant, e a filosofia continental de maneira geral] dentro de casa e não fora de portas), que Rorty contrapõe (de um modo que não é relevante para nós aqui analisarmos em detalhe) a uma outra, pós-moderna, que ele próprio desenvolverá, na sequência do pragmatismo de James e de Dewey, da filosofia de Heidegger, e das de outros, e que, em parte pelo menos, vai ao encontro das Investigações de Wittgenstein (uma obra "pós-moderna", num registo como o do filósofo americano em 1979, i.é, uma obra em que se abandonará, em contraste com o Tractatus, essa conceção fundacional e sistemática a que aludi). ${ }^{39} \mathrm{~A}$ conceção de Rorty, que eleva ao primeiro plano, balanços como aqueles que tinham sido feitos por Quine em diversos trabalhos nos anos sessenta, como é o caso de Relatividade ontológica e outros ensaios, é que a filosofia analítica não conseguiu atingir os seus desideratos, em matéria, designadamente, de teoria da significação, não tanto (ou não só) porque se tenha visto envolvida nas mesmas dificuldades, inconsistências e contradições da filosofia continental (esta conclusão, que não deixa de ser verdadeira e pertinente, foi tirada por outras historiografias da mesma época, como é o caso da de Katz e da de Coffa), ${ }^{40}$ mas porque o projeto moderno, fundacional e sistemático, de matriz cartesiana e kantiana, ele mesmo não é exequível. A filosofia, por via da lógica ou de qualquer outra maneira, não pode nem deve oferecer fundações para o que quer que seja, como ambiciosa e generosamente e se presumiu desde Descartes e de Kant.

\subsection{Dialética das grelhas de leitura do Tractatus}

Chamemos a esta leitura da filosofia contemporânea à luz da distinção entre modernidade e pós-modernidade, e, em especial, da questão de saber que fundações pode a filosofia oferecer para o conhecimento e a ação hu-

38 Immanuel Kant, Crítica da razão pura, trad. A. Morujão e M. Pinto dos Santos (Lisboa: Fundação Gulbenkian, 1989), 88 e ss.

39 Rorty, Philosophy, cap. VIII, 357 e ss.

40 Veja-se Jerrold Katz, The Metaphysics of Meaning (Cambridge-Massachusetts/ London: The MIT Press, 1990): e Albert Coffa, The Semantic Tradition from Kant to Carnap: To the Vienna Station (Cambridge: Cambridge University Press, 1995). 
mana, uma leitura "pós-moderna". (O termo começou por ser utilizado por F. Lyotard mais ou menos na mesma altura da publicação de A filosofia e $o$ espelho da natureza. $)^{41}$ Essa questão, insisto, é o tema central da modernidade. Indiscutivelmente, quer o programa de investigação de Russell, de 1900 em diante, quer o de Wittgenstein no Tractatus e em contraste com as Investigações, são modernos, no sentido em que ambos podem ser lidos à luz do paradigma fundacionalista em filosofia, que, como já referi, é compreendido de forma diferente nos dois casos. Sobre isso direi alguma coisa mais adiante. Do que se trata, com uma leitura como a de Rorty é, mais uma vez, de uma grelha de interpretação, quer dizer, da explanação de pressupostos na perspetiva dos quais devemos enquadrar e interpretar a filosofia contemporânea, e a analítica em particular (com a tese de que ela mesma terá chegado ao seu fim), na história da filosofia ocidental no seu conjunto. ${ }^{42}$ A historiografia analítica, com a sua obsessão ideológica pela ideia de que fará parte de uma tradição filosófica completamente divorciada dessa história, não pode reclamar de forma alguma chegar ao mesmo resultado fundamental. Mas a questão da modernidade a respeito das fundações (a de Kant, na Crítica da razão pura, será : “O que é que eu posso conhecer?"), não é apenas uma questão teórica ou metafilosófica: é também social, cultural e política, que tem a ver com a época (ou épocas) em que foi colocada. (É deste último ponto de vista que ela é importante para Lyotard.) Muito em especial, e tendo em vista uma obra como o Tractatus, é também (como mostrou Toulmin em A Viena de Wittgenstein) uma questão ética, uma questão sobre o sentido da vida e da existência humana. ${ }^{43}$ (O Tractatus começa por ser uma obra moderna, no sentido rortiano do conceito, justamente porque a filosofia, nela, abrange todos os campos da filosofia tradicional, aí incluindo a ciência e a ética, embora, como se verá, tal aconteça de uma forma completamente inovadora.) Tudo isto não significa, como comecei por dizer na introdução a este artigo, que devamos pôr completamente de lado a grelha de leitura oferecida pela historiografia analítica. A conceção segundo a qual o problema nuclear do Tractatus é a teoria da significação, antecipando-se desse modo, nesse livro, as Investigações filosóficas, pode e deve ser revisitada e reformulada no âmbito da modernidade e da questão das fundações. Também não se segue do que foi dito que a conceção clássica, dos anos trinta aos sessenta do século passado, de acordo com a qual essa obra se integrará no âmbito do programa da "filosofia do atomismo lógico", de Russell, deva ser descartada: uma parte

41 François Lyotard, La condition postmoderne. Rapport sur le savoir (Paris: Éditions de Minuit, 1979).

42 Ver Rorty, Philosophy, 3-13.

43 Veja-se Stephen Toulmin and Allan Janik, Wittgenstein's Vienna. (New York: Simon and Schuster, 1973), 239 e ss. 
do Tractatus, pelo menos, só é inteligível a partir dessa conceção. O essencial, quanto à hermenêutica dessa obra, é que, qualquer que seja a grelha de leitura, ela será útil desde que nos permita efetivamente compreendê-la, na totalidade e respetivas partes, no contexto da história da filosofia ocidental. E esse objetivo, evidentemente, pode passar por uma dialética das grelhas, por uma confrontação entre as mesmas, quando tal parecer pertinente para a melhor interpretação dos textos em estudo e apreço.

\section{O Tractatus e as fundações da filosofia}

Deste ponto de vista, a primeira coisa a fazer é pôr completamente de lado a teoria da historiografia analítica segundo a qual, por altura do Tractatus, não haveria quaisquer compromissos substantivos, constitucionais, entre o programa de investigação de Russell, por um lado, e o de Wittgenstein, por outro, porque o que justamente acontece, nessa obra, é que se procuram oferecer novas fundações para a ideia do filósofo inglês, a partir de 1900 e de Os princípios da matemática (1903) a O nosso conhecimento do mundo externo (1914) e a "Lições sobre a filosofia do atomismo lógico" (1918), passando pelos Principia Mathematica (1910-1913), de que a lógica (a "lógica matemática", ou a "lógica formal" ou "simbólica", como também foi designada correntemente na segunda metade do século XX) está no cerne das fundações do conhecimento e da ação humana de maneira geral, ou de que essas fundações só podem ser oferecidas por meio dela. (Em Russell, como investigações especializadas mostraram à exaustão até hoje, o seu programa [o chamado "logicismo"] assenta basicamente na tentativa de resolução e superação das contradições que envolviam certas partes da matemática, como a teoria dos conjuntos, nos finais do século XIX ${ }^{44}$ A teoria desse filósofo é que só a lógica matemática, não a metafísica tradicional [ou o que ele em alguns textos chamará uma "teoria da substância"], conseguirá fazê-lo. ${ }^{45}$ Ele consubstanciará o seu programa na ideia de que a "lógica é a essência da filosofia", ${ }^{46}$ que Wittgenstein, à sua maneira, subscreverá explícita e eloquentemente em várias secções do Tractatus. Não poderia haver à partida, nesta obra, nada de mais caracteristicamente russelliano do que uma tal ideia. Dizendo que a lógica está no cerne das fundações a que

44 Yvor Grattan-Guiness (ed.), Companion Encyclopedia of the History and Philosophy of the Mathematical Sciences (Baltimore and London: The John Hopkins University Press, 1994), 617 e ss.

45 Veja-se Bertrand Russell, La philosophie de Leibniz: Exposée critique, trad. J. Ray et R. Ray (Paris: Félix Alcan, 1908), cap. IV, 44 e ss.

46 Veja-se Russell, Our Knowledge, cap. 2. 
aludi, quer-se dizer, em sentido moderno e kantiano, e quanto a Russell em especial, que é através da lógica que se apresentam as "condições de possibilidade" da matemática e, na medida em que esta é a linguagem da física e do conhecimento científico de maneira geral, é através dela (lógica) que se apresentam as condições de possibilidade do conhecimento humano ele mesmo no seu conjunto (e, por esta via, também as da ética propriamente dita). No Tractatus, é certo, não se trata apenas-como em Russell e na filosofia tradicional e é corretamente alegado pela historiografia analítica-do tema do "conhecimento", que suscita interrogações epistemológicas inevitáveis, mas do de "linguagem" e do de teoria da significação muito em particular. (É neste sentido que o atomismo lógico, nessa obra, deve ser reinterpretado: não é, para Wittgenstein, uma matéria epistemológica que tenha a ver com o conhecimento [com o conhecimento direto e imediato do mundo, ou com a "acquaintance" russelliana], mas com uma outra, essencialmente semântica, que diz respeito às fundações da linguagem e da própria lógica.) Mas isso não significa de modo algum que Wittgenstein tenha ignorado ou contornado no Tractatus e ao encontro das Investigações filosóficas, a problemática tradicional da filosofia; ou aquilo a que hoje em dia podemos chamar "a problemática da modernidade filosófica", em leituras como as de Rorty e de outros. Como se sugeriu, é pela recolocação das questões tradicionalmente epistemológicas como questões semânticas, como questões sobre a significação na linguagem corrente, que passa, sem dúvida, a revolução do Tractatus (uma revolução silenciosa até aos anos setenta do século passado, como sugerimos na segunda secção deste artigo). Aí se inclui o relevo dado à física e à mecânica em particular na interpretação que foi dada a esta última pelos Princípios da mecânica de H. Hertz: ${ }^{47}$ do que se trata, como acontece no paradigma cartesiano e kantiano, é da ideia de que não só a matemática mas também a física, quando filosófica ou metafisicamente retomadas, constituem o quadro mediante o qual se devem compreender as condições de possibilidade do conhecimento humano de maneira geral, porque justamente é num tal quadro (o dos "juízos sintéticos a priori" de Kant) que esse conhecimento será universal e necessário. ${ }^{48}$ (O campo da física, na Crítica da razão pura, é basicamente o das leis do movimento de Newton, cuja

47 Veja-se Heinrich Hertz, The Principles of Mechanics presented in a New Form, (London: MacMillan of London, 1890). Veja-se Ludwig Wittgenstein, Tractatus LogicoPhilosophicus, with an Introduction by Bertrand Russell (London: Kegan Paul, 1933), 71 (4.04), 173-175 (6.341), 175-177 (6.342).

48 Kant, Crítica, 175 e ss. Veja-se uma aplicação desta ideia ao positivismo lógico feita por Michael Friedman, "Philosophy and the Exact Sciences: Logical Positivism as a Case Study", in: Inference, Explanations and other Frustrations: Essays in Philosophy of Science, ed. John Earman (Berkeley: University of California Press,1992), 84-98. 
justificação é feita precisamente no quadro da "lógica transcendental" e da "analítica dos princípios" em especial.) Mas uma interpretação similar poderia ser dada quanto à ética nas duas últimas secções do Tractatus: ela, como acontece nesse paradigma e em particular na versão kantiana da Crítica, só é abordada-"sistematicamente" diria eu-uma vez dirimida a questão de saber o que é que se segue da problemática propriamente dita do conhecimento, isto é, depois de esta ter sido semanticamente reinterpretada no seu conjunto. Será, desse ponto de vista sistemático, a última e a parte mais fundamental da filosofia. (foi, de resto, dessa maneira que o próprio Wittgenstein sempre a entendeu.) $\mathrm{O}$ território semântico da filosofia, no Tractatus, cobre inteiramente, senão mesmo mapeia campo a campo, os territórios epistemológico e metafísico da filosofia tradicional. Isso, evidentemente, não acontece por acaso. Como sugeriu Pears pertinentemente em A falsa prisão (e Toulmin, por sua vez, em $A$ Viena de Wittgenstein, defenderá), a questão kantiana da Crítica da razão pura pode ser reformulada ainda num sentido essencialmente moderno: em vez de "O que é que eu posso conhecer?", a verdadeira pergunta será "O que é que eu posso dizer?; ou, mais precisamente, "O que é que eu posso dizer com sentido?" 49 Deste ponto de vista, já o dissemos, não saímos ainda completamente da modernidade e das questões metafilosóficas que estão na sua base, como aquelas que dizem respeito diretamente a Russell. O programa fundacionalista russelliano da lógica como "essência da filosofia", em $O$ nosso conhecimento do mundo externo e trabalhos seguintes, é metafilosoficamente retomado, no Tractatus, como um programa sobre as fundações da própria filosofia através da lógica: "Logic fills the world: the limits of the world are also its limits.-We cannot therefore say in logic: This and this there is the world, that there is not.-For that would apparently presuppose that we exclude certain possibilities, and this cannot be the case since otherwise logic must get outside the limits of the world: that is, if it could consider these limits from the other side also.-What we cannot think, that we cannot think; we cannot therefore say what we cannot think." ${ }^{50} \mathrm{E}$ neste sentido fundacionalista último, e só neste sentido, que a lógica no Tractatus, em contraste com o que acontece nas Investigações, é despedida por Wittgenstein: não se trata, para ele, de menorizar ou desvalorizar o papel da mesma, como alguma historiografia analítica sugere, mas, pelo contrário, de a entronizar e elevar ao primeiro plano da reflexão filosófica.

49 Veja-se Pears, The False Prison, Part I. E Toulmin and Janik, Wittgenstein's Vienna, 167 e ss.

50 Wittgenstein, Tractatus, 149 (5.61). 


\subsection{O Tractatus e a ideia de uma "lógica filosófica"}

É neste amplo contexto que devemos ler e (sobretudo) reinterpretar o próprio título do Tractatus: "Tractatus Logico-Philosophicus" e a ideia (enigmática à primeira vista) de uma "lógica filosófica" em particular. Como e porque é que a lógica há-de ser "filosófica? Não é verdade que ela, segundo a historiografia analítica, é basicamente um património do século XX e das fundações da matemática em especial? Que a lógica, muito antes ainda de se ter tornado "matemática", com Frege e com Russell, constituía a matriz fundacional da filosofia, a que me referi antes, é algo patente na segunda parte da Crítica da razão pura de Kant, intitulada precisamente "lógica transcendental". Trata-se já de uma "lógica filosófica": a lógica identifica-se com os processos discursivos da razão pura, na medida em que esta visa justificar, através da matemática e da física, a possibilidade do conhecimento e da ação humana de maneira geral. ${ }^{51}$ (A questão de saber como é que chegámos até a esta conceção fundamental, do ponto de vista da história e das historiografias da lógica, não pode ser discutida neste artigo. O que acontece é que, na sequência do impacto da filosofia analítica, as historiografias mais relevantes na segunda metade do século XX, como é o caso das de Bochenski, Kneale e Kneale, e Blanché, ignoram pura, ostensiva e grosseiramente a ideia de uma "lógica filosófica" e os contributos de Descartes, Kant, Hegel e outros para a mesma. Isso é surpreendente e mesmo paradoxal, mas é um facto incontroverso. $)^{52} \mathrm{O}$ idealismo absoluto alemão, ao abrigo da eliminação da distinção entre fenómeno e númeno, vai expandir o conceito kantiano de lógica, e esta aparece-nos, em Hegel, propriamente como uma "ciência". ${ }^{53}$ Mas já sem nos falar de lógica e associar esta à filosofia, o objetivo fundamental de Descartes nas Meditações e, particularmente, nos Princípios da filosofia, era, de forma latente, o mesmo de Kant: no último livro, como se disse mais acima, Descartes apresenta-nos a famosa "árvore do conhecimento", em que a filosofia (ou a metafísica) é o tronco de que as diferentes ciências serão os ramos; é à filosofia, pois, que compete a fundação das restantes ciências e do conhecimento no seu conjunto. ${ }^{54} \mathrm{O}$ desiderato cartesiano, kantiano e hegeliano sobre as fundações, como mostraram Rorty e outros nos

51 Kant, Crítica, 88 e ss.

52 Veja-se Innocentius M. Bochenski, A History of Formal Logic (University of California: Notre Dame Press, 1961); Robert Blanché, La logique et son histoire d'Aristote à Russell (Paris, Armand Colin, 1970); William Kneale e Martha Kneale, O desenvolvimento da lógica, trad. M. S. Lourenço (Lisboa, Ed. Gulbenkian, 1972).

53 Veja-se Georg W. F. Hegel, Science of Logic, transl. A. V. Miller (London: Allen \& Unwin, 1969).

54 Cf. nota 37. 
anos oitenta do século passado, marca indelével e decisivamente a modernidade filosófica de maneira geral até à época propriamente contemporânea e ao começo da pós-modernidade, já depois da Segunda Grande Guerra; e é através dele, como já sugerimos, que devemos enquadrar as investigações de Russell em matéria de lógica a partir de 1900 com Os princípios da matemática e obras seguintes. (Como será ainda através dele, de acordo com a historiografia de Rorty, que devemos começar por enquadrar-sob pena de não as compreendermos finalmente-as investigações de Carnap, de Quine, de Lakatos, de Feyerabend, e de outros, já na segunda metade do século XX, isto é, já no contexto da pós-modernidade em filosofia. $)^{55}$ Russell, recorde-se, tinha sido um neo-hegeliano antes dos 1900s, altura em que, como ele nos diz na sua autobiografia intelectual, quando se tratava de decidir entre Hegel e Kant, tomava geralmente "o partido" do primeiro grande filósofo. ${ }^{56}$ Esse neo-hegelianismo e o desiderato das fundações, como defendi noutros lados, atravessa a sua filosofia, mais ou menos sub-repticiamente, praticamente desde o início até ao fim (em rigor, só há filosofia para Russell no sentido fundacionalista e sistemático do conceito, o que significa que ele rejeitaria, desde logo, conceções como as das Investigações filosóficas de Wittgenstein.). ${ }^{57} \mathrm{~A}$ ideia matriz do que se tornou usual chamar "logicismo" é que a lógica matemática passa a ocupar agora, em novos termos, o papel que competia tradicionalmente à filosofia e à metafísica em particular: na medida em que a física pode ser reduzida à matemática, e esta, por sua vez, pode ser reduzida à lógica (como mostraram Frege e o próprio Russell), esta última constituirá a fundação última do conhecimento e da ação humana no seu conjunto. ${ }^{58}$ Mas essa lógica matemática de Russell era já, à sua maneira, uma "lógica filosófica", no sentido wittgensteiniano do conceito no Tractatus. A lógica, como vimos mais acima e se diz em $O$ nosso conhecimento do mundo externo, constituirá a "essência da filosofia", porque tudo o que há a dizer sobre esta última, qualquer que seja o domínio em questão (e aí incluindo a ética), passa fundamentalmente por ela de um modo ou de outro. (Como se mostrou, Wittgenstein, com o Tractatus não dirá outra coisa [enigmaticamente mais uma vez, à primeira vista].) Era uma ideia otimista, desde o início, quer dizer, desde Os princípios da Matemática: a redução da matemática à lógica ia a par da pretensão de eliminar ou, pelo menos, clara-

55 Veja-se Rorty, Philosophy, 315-355.

56 Russell, My Philosophical, cap. 2.

57 Veja-se Ribeiro, Bertrand, 31-41.

58 Henrique Jales Ribeiro, "O mito da redução da matemática à lógica: Cem anos depois de Os princípios da matemática (1903-2003)", in: Actas do $1^{\circ}$ Encontro Nacional de Filosofia Analitica, org. Henrique Jales Ribeiro (Coimbra: Unidade de I\&D Linguagem, Interpretação e Filosofia (FCT), 2003), 143-155. 
mente delimitar, os papéis da epistemologia e da metafísica tradicionais, aí incluindo as do próprio Kant e a sua noção de "sintético a priori" em especial (a grande bandeira do filósofo inglês nesse livro). ${ }^{59}$ (É um tal "programa" que o positivismo lógico vienense vai procurar desenvolver a partir dos meados dos anos vinte, através de Carnap e de Schlick sobretudo, como de resto atesta, em 1929, o manifesto do "Círculo de Viena". ${ }^{60}$ Mas, por outro lado, como sugerirá Wittgenstein ainda antes do Tractatus a propósito de múltiplas questões relacionadas com a filosofia de Russell na altura (designadamente o manuscrito desse filósofo sobre a "Teoria do conhecimento"), e deixando de lado os detalhes, era uma ideia claramente inconsistente e contraditória em si mesma, porque, à partida, a sua vocação não poderia deixar de ser epistemológica e metafisica: a filosofia do atomismo lógico e o programa da "construção do mundo eterno", de Russell, atestam precisamente isso mesmo. ${ }^{61}$ É possível justificar a lógica como fundação última para o conhecimento e a ação humana, sem nos vermos envolvidos nas dificuldades e contradições que caracterizam um projeto como o de Russell? É este o desiderato, de fundo cartesiano e kantiano, mas também de forte embebência russelliana, do Tractatus.

\section{Conclusão}

Como se mostrou, a questão de saber qual é o lugar do Tractatus na história da filosofia ocidental está longe de ser pacífica e inofensiva. A chamada "história da filosofia analítica" oferece uma resposta inaceitável a essa

59 Bertrand Russell, The Principles of Mathematics (London: Routledge, 1992), 456$-461$.

60 Veja-se Otto Neurath, "The Scientific Conception of the World" (1929), in: Empiricism and Sociology, ed. M. Neurath and R. Cohen (Dordrecht-Holland/Boston-USA, Reidel Publishing Company, 1973), 305-313. E Henrique Jales Ribeiro, "Kant, os começos da filosofia analítica e o Wiener Kreis", Revista Portuguesa de Filosofia (Herança de Kant) 61 (2005), 883-899; idem, "Kant e o positivismo lógico vienense: O manifesto do 'Círculo de Viena' como caso em estudo", in: Actas do Colóquio Internacional 'Kant 2004: Actualidade e Posteridade' (Lisboa: Faculdade de Letras da Universidade de Lisboa, 2006), 589-600.

61 Veja-se Bertrand Russell, Bertrand Russell: Theory of Knowledge. The 1913 Manuscript, The Collected Papers of Bertrand Russell, vol. 7, ed. Elisabeth R. Eames (London and New York: Routledge, 1984); e Elisabeth R. Eames, Bertrand Russell's Dialogue with His Contemporaries (Carbondale and Edwardsville (USA): Southern Illinois University Press, 1989), 143-159. Sobre o enquadramento filosófico a que aludimos, na época e na perspetiva de Wittgenstein em especial, veja-se Ludwig Wittgenstein, Notebooks: 1914-1916, ed. G. H. von Wright and G. E. M. Anscombe (Oxford: Blackwell, 1969); e idem, Letters. 
questão, que significa e implica, para todos os efeitos, romper mais ou menos completamente com a primeira. Esta não começa com Frege, Russell ou Wittgenstein, mas justamente com Sócrates, Platão e Aristóteles, e tem uma viragem decisiva, com a modernidade, através de Descartes e de Kant, que é essencial para se poder compreender a época contemporânea, e o que Lyotard, Rorty e outros chamaram, para a posteridade, "pós-modernidade". É na perspetiva destes últimos contextos que devemos ler, hoje em dia, o Tractatus, como aliás sugere o próprio Witttgenstein ainda antes da publicação dessa obra, na sua correspondência com Russell, a propósito da sua obra e da de Kant (num texto que serviu de epígrafe a este trabalho.). Mas tudo isto não acarreta que a grelha de leitura da filosofia analítica não possa ser útil ou proveitosa; muito menos que a devamos descartar inteiramente. (O mesmo, de resto, dissemos a respeito de outras grelhas alternativas e competitivas.) A ideia, da historiografia analítica, de que a teoria da significação e a problemática da linguagem de maneira geral são os temas centrais do Tractatus, é pertinente e relevante, quando enquadrada naquele que era o maior e mais essencial problema para Wittgenstein: o das fundações últimas da filosofia através da lógica (e das conceções desta por parte de Frege e de Russell em especial). Só do ponto de vista da referida teoria, como vimos, é que se pode dizer, com alguns limites ou reservas que analisámos atentamente, que o Tractatus antecipa as Investigações filosóficas. Essa obra fecha ou encerra, a seu modo, o grande ciclo da modernidade filosófica inaugurado por Descartes e por Kant, e do qual é seguramente, ao lado das Meditações e da Crítica da razão pura, um dos maiores expoentes.

\section{Referências Bibliográficas}

Arrington, Robert L., and Glock, Hans-Johann. (eds.), Wittgenstein and Quine. London and New York: Routledge, 1996.

Ayer, Alfred J. "The Analytic Movement in Contemporary Brirish Philosophy", in: Actes du Congrès International de Philosophie Scientifique (Sorbonne). Paris: Hermann, 1935.

Ayer, Alfred J. The Foundations of Empirical Knowledge. London: MacMillan, 1940.

Ayer, Alfred. Russell and Moore: The Analytic Heritage. London: MacMillan, 1971. Ayer, Alfred J. et al. (eds.), The Revolution in Philosophy. London: MacMillan, 1956. Bochenski, Innocentius M. A History of Formal Logic. University of California: Notre Dame Press, 1961.

Blanché, Robert. La logique et son histoire d'Aristote à Russell. Paris, Armand Colin, 1970.

Coffa, Albert. The Semantic Tradition from Kant to Carnap: To the Vienna Station. Cambridge: Cambridge University Press, 1995. 
Descartes, René. The Philosophical Writings of Descartes, vol. I, transl. J. Cottingham, R. Stoothoff, and D. Murdoch. Cambridge: Cambridge University Press, 1985.

Dummett, Michael. Truth and other Enigmas. London: Duckworth, 1978.

Dummett, Michael. Frege: Philosophy of Language. London: Duckworth, 1981 [1973].

Dummett, Michael. Les origines de la philosophie analytique, trad. M.-A. Lescourret. Paris: Gallimard, 1991.

Eames, Elisabeth R. Bertrand Russell's Dialogue with His Contemporaries. Carbondale and Edwardsville (USA): Southern Illinois University Press, 1989.

Flew, Anthony (ed.). Logic and Language. Oxford: Basil Blackwell, 1953.

Follesdal, David. "Analytic Philosophy: What is and Why Should One Engage on It ?", in: The Rise of Analytic Philosophy, ed. Hans-Johann Glock. Oxford: Blackwell Publlisers Inc., 1997, 193-208.

Friedlander, Eli. Signs of Sense: Reading Wittgenstein's 'Tractatus'. Cambridge-Massachusetts/London: Harvard University Press, 2001.

Friedman, Michael. "Philosophy and the Exact Sciences: Logical Positivism as a Case Study", in: Inference, Explanations and other Frustrations: Essays in Philosophy of Science, ed. John Earman. Berkeley: University of California Press, 1992, 84-98.

Gellner, Ernest. Words and Things. A Critical Account of Linguistic Philosophy, and a Study in Ideology, with and Introduction by Bertrand Russell. Bungay-Suffolk (UK): Victor Gollancz, 1959.

Glock, Hans-Johann. What is Analytic Philosophy? Cambridge: Cambridge University Press, 2008.

Glock, Hans.-Johann. org., The Rise of Analytic Philosophy. Oxford: Blackwell Publlisers Inc., 1997.

Grattan-Guiness, Ivor. Companion Encyclopedia of the History and Philosophy of the Mathematical Sciences. London: Routledge, 1994.

Gueroult, Martial. Dianoématique (Livre II: Philosophie de l'histoire de la philosophie. Paris: Aubier, 1979.

Hacker, Peter. Wittgenstein's Place in Twentieth-Century Analytic Philosophy. Oxford: Blackwell, 1996.

Hacker, Peter. Wittgenstein: Connections and Controversies. Oxford: Clarendon Press, 2011

Hegel, Georg W. F. Science of Logic, transl. A. V. Miller. London: Allen \& Unwin, 1969 [1812-1816].

Hertz, Heinrich. The Principles of Mechanics presented in a New Form. London: MacMillan of London, 1890.

Hylton, Peter. "Logic in Russell's Logicism", in: The Analytic Tradition: Meaning, Thought, and Knowledge, ed. David Bell and Neil Coopper. Cambridge-Massachusetts, 1990, 137-192.

Iglesias, Teresa. "Russell's Introduction to Wittgenstein's Tractatus", Russell: The Journal of the Bertrand Russell's Archives 25-28 (1977), 21-38.

Iglesias, Teresa. "Russell and Wittgenstein: Two Views of Ordinary Language", Philosophical Studies XVIII (1981), 148-163. 
Kant, Immanuel. Crítica da razão pura, trad. A. Morujão e M. Pinto dos Santos. Lisboa: Fundação Gulbenkian, 1989 [1781-1787]

Katz, Jerrold. The Metaphysics of Meaning. Cambridge-Massachusetts/London: The MIT Press, 1990.

Kneale, Willian, e Kneale, Martha. O desenvolvimento da lógica, trad. M. S. Lourenço. Lisboa: Ed. Gulbenkian, 1972.

Kuhn, Thomas. The Structure of Scientific Revolutions. Chicago: Chicago University Press, 1962.

Kuhn, Thomas. A tensão essencial, trad. R. de Pacheco. Lisboa: Edições 70, 1989.

Lewis, H. D. (ed.), Clarity is not Enough: Essays in Criticism of Linguistic Philosophy. London: George Allen \& Unwin Ltd., 1963.

Lyotard, François. La condition postmoderne. Rapport sur le savoir. Paris: Éditions de Minuit, 1979.

Martinich, A. P., and Sosa, David. (eds.), A Companion to Analytic Philosophy. Oxford: Blackwell Publishers, 2001.

Mulligan, Kevin. "Sur l'histoire de l'approche analytique de l'histoire de la philosophie (de Bolzano et Brentano à Bennett et Barnes", in: Philosophie analytique et histoire de la philosophie, ed. Jean-Michel Vienne. Paris: Vrin, 1997, 61-84.

Mulligan, Kevin. "Introduction: On the History of Continental Philosophy", Topoi 2 (2009), 115-120.

Neurath, Otto. "The Scientific Conception of the World" (1929), in: Empiricism and Sociology, ed. M. Neurath and R. Cohen. Dordrecht-Holland/Boston-USA, Reidel Publisihing Company, 1973, 305-313.

Pears, David. "Logical Atomism: Russell and Wittgenstein", in: The Revolution in Philosophy, ed. Alfred J. Ayer et al. London: MacMillan, 1956, 41-55.

Pears, David. The False Prison. A Study of the Development of Wittgenstein's Philosophy. Oxford: Oxford University Press, 1987.

Quine, Willard van O. "Two dogmas of Empiricism”, in: From a Logical Point of View. Cambridge-Massachusetts: Harvard University Press, 1-19.

Quine, Willard van O. "Le mythe de la signification”, in: La philosophie analytique, org. Jean Wahl et al. Paris: Les Éditions de Minuit, 1962, 138-169.

Quine, Willard van O. Ontological Relativity and Other Essays. New York: Columbia University Press, 1969.

Rée, Jonathan. "La philosophie anglaise des années cinquante", in: Philosophie analytique et histoire de la philosophie, ed. Jean-Michel Vienne. Paris: Vrin, 1997, 17-59.

Ribeiro, Henrique Jales. “Da 'imagem oficial' de Russell à reabilitação da sua filosofia: 'O vago' como caso em estudo", in: Da natureza ao sagrado (homenagem a Francisco Vieira Jordão). Porto: Fundação Eng. António de Almeida, 1999, 199-257.

Ribeiro, Henrique Jales. "Towards a Reformulation of the Analytic Concept of the History of Philosophy", in: Proceedings of the International Congress 'Analytic Philosophy at the Turn of the Millenium". Santiago de Compostela: Universidad de Santiago de Compostela, 1999, 493-501.

Ribeiro, Henrique Jales. Para compreender a história da filosofia analítica. Coimbra: MinervaCoimbra, 2001. 
Ribeiro, Henrique Jales. "Russell, o Tractatus de Wittgenstein, e o problema do holismo em filosofia", Revista Portuguesa de Filosofia 58 (2002), 465-495.

Ribeiro, Henrique Jales. "O mito da redução da matemática à lógica: Cem anos depois de Os Princípios da matemática (1903-2003)", in: Actas do $1^{\circ}$ Encontro Nacional de Filosofia Analítica, org. Henrique Jales Ribeiro. Coimbra: Unidade de I\&D Linguagem, Interpretação e Filosofia (FCT), 2003, 143-155.

Ribeiro, Henrique Jales. “A New Reading of Russell's 'Introduction' to Wittgenstein's Tractatus", in: Time and History: Papers of the 28th International Wittgenstein Symposium, eds. Friedrich Stadler and Michael Stöltzner. Kirchberg am Wechsel: Austrian Ludwig Wittgenstein Society, 2005, 256-257.

Ribeiro, Henrique Jales. "Locke, a tradição do empirismo britânico e a filosofia analítica", in: Actas do Colóquio Internacional 'A Herança de Locke' (Proceedings of the International Colloquium 'Locke's Legacy'). Lisboa: Faculdade de Letras da Universidade de Lisboa, 2005, 39-60.

Ribeiro, Henrique Jales. "Kant, os começos da filosofia analítica e o Wiener Kreis", Revista Portuguesa de Filosofia (Herança de Kant) 61 (2005), 883-899.

Ribeiro, Henrique Jales. "Russell, Wittgenstein e a ideia de uma 'linguagem logicamente perfeita", Revista Filosófica de Coimbra 27 (2005), 81-130.

Ribeiro, Henrique Jales. "Kant e o positivismo lógico vienense: O manifesto do 'Círculo de Viena' como caso em estudo", in: Actas do Colóquio Internacional 'Kant 2004: Actualidade e Posteridade'. Lisboa: Faculdade de Letras da Universidade de Lisboa, 2006, 589-600.

Ribeiro, Henrique Jales. Bertrand Russell e a Filosofia Analítica no Século XX. Coimbra: Pé de Página Editores, Lda., 2007.

Ribeiro, Henrique Jales. "Não há método nem métodos da filosofia analítica: Não há filosofia analítica", in: Actas do Colóquio "Método e Métodos do Pensamento Filosófico' (Faculdade de Letras da Universidade de Coimbra, 26-27 de abril de 2006), org. Diogo Ferrer. Coimbra: Imprensa da Universidade de Coimbra, 2007, 119-135.

Ribeiro, Henrique Jales. "Russell vs. Wittgenstein: In Defense of Russell (A Reply to Some Old Thesis of Peter Hacker's Interpretation of Wittgenstein's Tractatus)", in: Image and Imaging in Philosophy, Science, and the Arts: Papers of the 33rd International Wittgenstein Symposium, eds. Elisabeth Nemeth, Richard Heinrich and Wolfram Pichler. Kirchberg am Wechsel: Austrian Ludwig Wittgenstein Society, 2010, 268-270.

Rorty, Richard. (ed.), The Linguistic Turn: Recent Essays in Philosophical Method. Chicago: The University of Chicago Press, 1975 [1967].

Rorty, Richard. Philosophy and the Mirror of Nature. Princeton (NJ): Princeton University Press, 1979.

Russell, Bertrand. La philosophie de Leibniz: Exposée Critique, trad. J. Ray et R. Ray. Paris: Félix Alcan, 1908.

Russell, Bertrand. Our Knowledge of the External World as a Field for Scientific Method in Philosophy. Chicago and London: The Open Court Publishing Co., 1914.

Russell, Bertrand. My Philosophical Development. London: Routledge, 1959. 
Russell, Bertrand. The Analysis of Mind. London: Gorge Allen \& Unwin, 1971 [1921].

Russell, Bertrand. "The Philosophy of Logical Atomism", in: Bertrand Russell: The

Philosophy of Logical Atomism and Other Essays (1914-1919), The Collected

Papers of Bertrand Russell, vol. 8, ed. John Slater. London: George Allen and Unwin, 1986, 160-244.

Russell, Bertrand. Bertrand Russell: Theory of Knowledge. The 1913 Manuscript, The Collected Papers of Bertrand Russell, vol. 7, ed. Elisabeth R. Eames. London and New York: Routledge, 1984.

Russell, Bertrand. The Principles of Mathematics. London: Routledge, 1992 [1903].

Toulmin, Stephen, e Janik, Allan. Wittgenstein's Vienna. New York: Simon and Schuster, 1973.

Urmson, James O. Philosophical Analysis: Its Development Between the Two World Wars. Oxford: Clarendon Press, 1956.

Urmson, James O. "Histoire de l'analyse", in: La philosophie analytique, org. Jean Wahl et al. Paris: Les Éditions de Minuit, 1962, 11-22.

Wahl, Jean et al. (org.), La philosophie analytique. Paris: Les Éditions de Minuit, 1962.

Wittgenstein, Ludwig. Tractatus Logico-Philosophicus, with an Introduction by Bertrand Russell. London: Kegan Paul, 1933 [1921].

Wittgenstein, Ludwig. Philosophical Investigations, ed. G.E.M. Anscombe and R. Rhees, transl. G.E.M. Anscombe. Oxford: Blackwell, 1953.

Wittgenstein, Ludwig. Notebooks: 1914-1916, ed. G. H. von Wright and G. E. M. Anscombe. Oxford: Blackwell, 1969.

Wittgenstein, Ludwig. Letters to Russell, Keynes and Moore, ed. G. H. von Wright. Oxford: Basil Blackwell, 1974.

von Wright, Georg H. The Tree of Knowledge and Other Essays. Leiden/New York/ Köln: E. J. Brill, 1993. 